November, and did well until about 7 th January, when he was noticed to leave some of his food. He continued this way up to the I 7 th, when he refused to eat anything except a little fresh hay and bran. In a couple of days more he refused eating altogether, and died on the 27 th January. When he first showed signs of not feeding he was treated for constipation, and got several large doses of physic with oatmeal gruel and flax-seed tea. His bowels responded well to the physics, and he was let out during the fine part of the day from the time he first showed any signs of illness, but he would never graze. He would walk very stiff and slow to some quiet place and lie down. His breathing was very laboured. He never showed any signs of acute pain and died without a struggle. On being opened all the abdominal viscera were found healthy, but on opening the chest the pericardial sac was found to be of an enormous size, and perforated by a piece of iron. The pericardial sac contained a large quantity of purulent foul-smelling fluid. The foreign body was a thin piece of iron nearly three inches long and about one third of an inch broad at its widest part.

\title{
A CASE OF MAL-FORMATION OF THE UTERUS IN A COW.
}

By William Robb, M.R.C.V.S., Glasgow.

THE subject of this note was an Ayrshire cow about six years old, which I delivered of a dead calf on 6th January last.

History.-In the spring of last year, she was noticed to be suffering from tympanites; when turned out to the grass, and often after being fed in the byre, she became hoven. The flatulency seemed to cause her little or no trouble, and soon subsided.

This continued more or less all summer, but towards the end of September her abdomen became permanently enlarged. She kept getting gradually worse, and on the I $5^{\text {th }}$ December I was called in.

I found the abdomen greatly enlarged, the distension being chiefly towards the left side. I was rather at a loss what to make of this ; that it was not food, or other equally firm matter, I was certain. I examined her for ascites, but the symptoms did not support this idea, and I concluded it was a case of chronic tympanites.

The owner then desired me to puncture the rumen, but I advised him to wait until she calved, in order to see what change that might bring about.

On the 6th January I was called in again, and found that in great measure the enlargement had disappeared. I was told, that on the day before ( 5 th) a whitish fluid had escaped per vaginam, and that the swelling then immediately disappeared, the change being best noticeable on the left side. Her appetite had not been very good of late, but after the above change she became ravenous. On the morning of the 6th a second quantity of fluid of a totally different character escaped from her, a membrane being passed at the same time. I may here state that she was due to calve on the 7 th.

Concluding that parturition was about to take place, I passed my 
hand into the uterus; and, just anterior to the os, I found the knees of the calf. Having got the legs into the vagina and secured them, I returned my hand into the uterus to search for the head of the foetus. This I found deviated towards the left flank of its own body. After getting it up to the os, I had great difficulty in bringing it through. Thinking that there might be some other cause besides the non-relaxed os, I passed my hand along the back of the foetus, and was greatly surprised to find a membrane dividing the uterus. By strong traction I finally got the calf away.

The division which I had felt induced me to return my hand into the uterus again, with the following result:-I found that the foetus had existed in the right half, for the placental membranes were there, and the cotyledons felt unusually large. The left half of the uterine cavity, which seemed larger than the right, contained no placenta, and was very rugose or uneven to the touch. At its fundus a very little fluid still remained. When passing my hand into this cavity, I was attracted by a thick strong band, that extended from its wall to the partition dividing the two cavities. To find the shape of this my hand had to flex itself into something like the figure six, as the band rolled on itself.

That the enlargement of the abdomen had been due to the accumulation of fluid in this cavity appears certain; but in the absence of an opportunity to make a post-mortem examination (the cow being still alive), some doubt must exist as to the nature of the cavity. It seems to me not improbable that it may be a case of mal-formation approaching nearly to a condition of double uterus.

\section{LOCAL AN ESTHESIA.}

By Henki C. Wilkie, F.R.C.V.S., F.Z.S., Bodmin, Cornwall.

IN the December number of the Journal Professor Walley gives a warning with respect to the use of cocaine in canine practice which, I think, is most well-timed, as I am not aware of any previous record of such cases. A somewhat similar instance to that which the Professor relates occurred in my own practice towards the end of 1889 .

The patient was a large and very powerful setter bitch, and the operation consisted in the removal of a small tumour situated in the mammary gland. In all previous cases of this kind I had used chloroform to produce general anæsthesia; and although I had never had occasion to fear untoward results, I, unfortunately, resolved to use cocaine in this instance. I employed a hypodermic syringe such as is used in human surgery (the needle of which had been passed through a spirit flame), and a I 5 per cent. solution of cocaine. This solution I injected in seven places around the base of the tumour, and awaited establishment of anasthesia, while the bitch was being held on her side as quietly as possible. In about three minutes the animal was seized with clonic convulsions, the tongue protruded, the lips were drawn away from the gums, and there was frothy salivation, while the eyes appeared unnaturally prominent, and the pupils were widely dilated. 